\title{
The Effect of Frenotomy on the Tongue Length, Motion, and Speech According to Age
}

\author{
Ju Eun Kim, Bo Ram Keum, Sung Won Li, Sung Min Park ${ }^{\mathbb{D}}$, \\ Bin Kwon, Heejin Kim, and Il-Seok Park (iD \\ Department of Otorhinolaryngology-Head and Neck Surgery, Hallym University College of Medicine, Dongtan Sacred Heart Hospital, \\ Hwaseong, Korea
}

연령에 따른 설소대 절제술 후 혀 길이와 운동성 및 자음정확도의 변화에 대한 연구

김주은 · 금보람 · 이성원 · 박성민 · 권 빈 · 김희진 · 박일석

한림대학교 의과대학 동탄성심병원 이비인후-두경부외과학교실

\author{
Received May 4, 2020 \\ Revised June 22, 2020 \\ Accepted July 3, 2020 \\ Address for correspondence \\ Il-Seok Park, MD, PhD \\ Department of Otorhinolaryngology- \\ Head and Neck Surgery, \\ Hallym University \\ College of Medicine, \\ Dongtan Sacred Heart Hospital, \\ 7 Keunjaebong-gil, \\ Hwaseong 18450 , Korea \\ Tel $+82-31-8086-2670$ \\ Fax $+82-31-8086-2709$ \\ E-mail ispark@hallym.or.kr
}

Background and Objectives Ankyloglossia often results in articulation disorders, which depends on age, articulation ability, and mobility of the tongue. A primary treatment strategy includes surgery and/or speech therapy. This study aimed to evaluate the changes of the tongue length, tongue mobility, and percentage of consonants correct (PCC) after frenotomy. We investigated the optimal surgery timing for ankyloglossia.

Subjects and Method A total of 136 patients underwent frenotomy for the tongue tie between January 2016 and December 2019. There were 90 males and 46 females, with the mean age of 5.23, which ranged from 2 to 10 years. The length of the tongue was measured for all patients during the operation preoperatively and postoperatively. The mobility of the tongue and PCC were performed preoperatively and 1 month after surgery by two speech therapists. Patients were divided according to age into three groups: 2-3 years, $4-5$ years, and over 6 years old. Results The mean tongue length of all age groups was significantly elongated after surgery $(p<0.05)$. After frenotomy, the mobility of tongue, including horizontal protrusion, protrusion with upward pointing, circumlocution, and lateral movement, was improved. Also, PCCs of all age groups were significantly improved after surgery $(p<0.05)$.

Conclusion Frenotomy can be an effective procedure for children with ankyloglossia in all age groups. After frenotomy, length of the tongue, mobility of the tongue and PCC were significantly improved.

Korean J Otorhinolaryngol-Head Neck Surg 2021;64(2):98-102

Key Words Ankyloglossia · Articulation disorders · Tongue diseases.

\section{서 론}

비정상적으로 짧은 설소대로 인해 혀 운동성 장애를 초래 하는 선천성 질환을 설소대 단축증(ankyloglossia) 또는 혀 유착증(tongue-tie)이라고 한다. 설소대 단축증은 혀의 운동 성을 방해하므로 발음 장애를 일으키는 원인으로 알려져 있

This is an Open Access article distributed under the terms of the Creative Commons Attribution Non-Commercial License (https://creativecommons.org/licenses/by-nc/4.0) which permits unrestricted non-commercial use, distribution, and reproduction in any medium, provided the original work is properly cited.
으며, 특히 치조음 중에서 'ㄹ', 'ㅅ', '쓰를 발음할 때 현저한 오 류를 보인다.1)

그동안 많은 연구를 통하여 설소대 단축증으로 인해 수유 곤란이나 발음 오류가 있을 때 설소대 절제술(frenotomy)을 시행하는 것이 도움이 된다고 알려져 왔다. ${ }^{2)}$ 우리나라의 경 우, 수유 곤란 없이도 심미적 요구나 발음 문제의 교정을 목 적으로 많은 수의 환아들이 설소대 절제술을 받고 있다. 몇 몇 연구들을 통해, 설소대 단축증 환아들에게 언어치료 없 이 수술적 치료만을 통해 혀 운동성 및 발음 개선이 보고된 
바 있으나, ${ }^{3,4}$ 적절한 수술 시기에 대한 근거가 미비하여 여전 히 논란이 되고 있다. Block ${ }^{5}$ 은 만 5세까지 수술적 치료를 보 류하고 추적 관찰하는 것이 적절하다고 주장하였다. 그러나 Lee 등 ${ }^{6}$ 은 연구 대상자 중 만 5세 이하도 수술 후 혀의 운동 성과 발음 명료도가 유의하게 개선된 결과가 나타나 이전 연 구와 상반된 결과를 보고하였다.

따라서 본 연구는 연령별 설소대 단축증 아동의 혀의 길이 및 운동성, 발음 명료도 향상의 변화를 술 전후로 비교하여 적절한 수술적 교정 시기에 대한 객관적인 근거를 제시하고자 하였다.

\section{대상 및 방법}

\section{대 상}

2016년 1월 2019년 12월까지 설소대 단축증을 주소로 본 원에 내원하여 설소대 절제술을 시행 받은 만 2세에서 만 10

Table 1. Pre- and post-operative tongue length and sex distribution of children with ankyloglossia

\begin{tabular}{lccccc}
\hline \multirow{2}{*}{ Age (year) } & \multicolumn{2}{c}{ Sex } & & \multicolumn{2}{c}{ Length $(\mathrm{cm})$} \\
\cline { 2 - 3 } \cline { 5 - 6 } \cline { 5 - 6 } & Male & Female & & Preoperative & Postoperative \\
\hline $2-3$ & 21 & 10 & & $0.77 \pm 0.36$ & $1.82 \pm 0.47$ \\
$4-5$ & 34 & 19 & & $0.82 \pm 0.29$ & $1.93 \pm 0.55$ \\
Over 6 & 35 & 17 & & $0.88 \pm 0.29$ & $1.99 \pm 0.49$ \\
Total/mean & 90 & 46 & & $0.83 \pm 0.31$ & $1.93 \pm 0.51$ \\
\hline
\end{tabular}
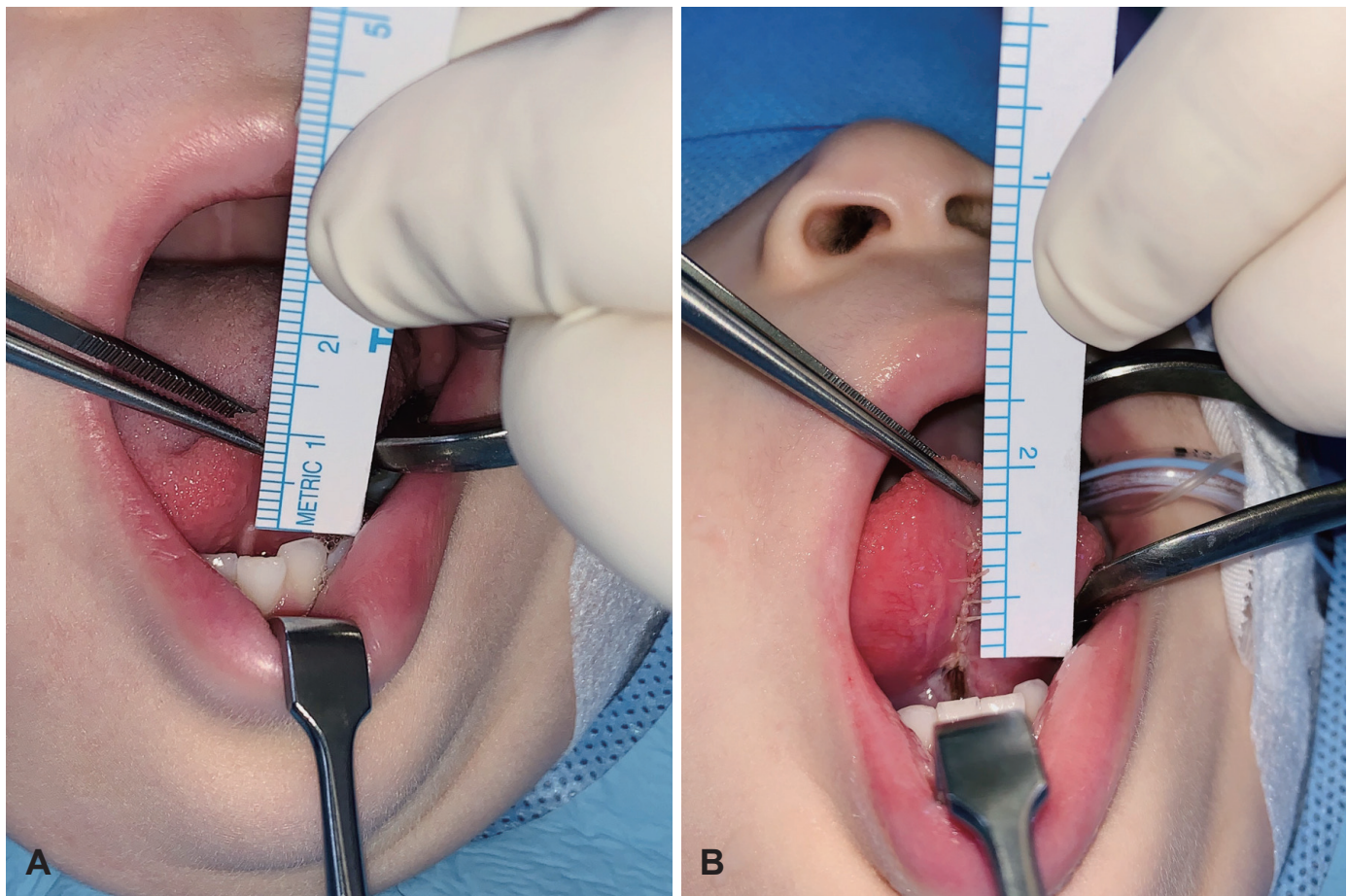

Fig. 1. Measuring the length of tongue: preoperative (A), postoperative (B).
세까지의 아동으로 수술 전과 수술 후 1 개월 뒤 자음정확도 평가 및 혀 운동성 평가를 시행한 환아, 총 136명을 대상으로 하였다. 대상자의 평균 연령은 $5.23 \pm 2.55$ 였고, 성별은 남자 90명, 여자 46명이었다. 대상자 중 구개열 등의 선천적 질환, 인지 및 행동 장애 등이 있거나 수술 전·후의 검사를 이해하 고 수행할 수 없는 아동은 대상에서 제외하였다. 연령별로 2 3세, 4 5세, 6세 이상의 세 그룹으로 나누었을 때, 2 3세 그룹은 남자 21명, 여자 10명, 4 5세 그룹은 남자 34명, 여자 19 명, 6세 이상은 남자 35 명, 여자 17 명으로 각 그룹당 남녀 의 비율은 큰 차이를 보이지 않았다(Table 1). 본 연구는 '헬 싱키선언'을 준수하였으며 동탄성심병원 기관의 연구윤리심 의위원회의 승인을 받았다(IRB No. 2020-03-019).

\section{방 법}

아동의 혀 길이 측정은 대상자의 혀끝(설첨)에서 설소대가 시 작되는 부위까지 자의 눈금을 읽어 길이를 기록하였다(Fig. 1). 이는 $\operatorname{Kim}$ 등 $^{7)}$ 이 고안한 방법으로 혀 길이를 $0.1 \mathrm{~mm}$ 단위로 측정하였다. 혀의 길이는 전신 마취를 시행한 상태에서 혀의 끝에 실을 tagging한 후 잡아당기지 않은 상태에서 수술 전 과 수술 직후에 각각 측정하여 기록하였다. 수술은 혀를 들 어올려 설소대를 관찰한 후 설소대의 섬유끈을 수술용 칼을 이용하여 박리하였으며, 악하선의 주행에 유의하여 절개면 의 점막층을 vicryl 4-0(Ethicon, Somerville, NJ, USA)으로 봉합하였다. 
Korean J Otorhinolaryngol-Head Neck Surg I 2021;64(2):98-102

Table 2. Pre- and postoperative tongue mobility of children with ankyloglossia

\begin{tabular}{|c|c|c|c|c|}
\hline Action & Age (year) & Preoperative (\%) & Postoperative (\%) & $p$-value \\
\hline \multirow[t]{3}{*}{ Horizontal protrusion } & $2-3$ & $5 / 31(16.12)$ & $14 / 31(45.16)$ & $0.003^{*}$ \\
\hline & $4-5$ & $11 / 53(20.75)$ & $41 / 53(77.36)$ & $<0.001^{*}$ \\
\hline & Over 6 & 18/52 (34.62) & $49 / 52(94.23)$ & $<0.001^{*}$ \\
\hline \multirow[t]{3}{*}{ Protrusion with upward pointing } & $2-3$ & $0 / 31(0)$ & $12 / 31(38.71)$ & $0.001^{*}$ \\
\hline & $4-5$ & $1 / 53(0.02)$ & $34 / 53(64.15)$ & $<0.001^{*}$ \\
\hline & Over 6 & 10/52 (19.23) & $45 / 52(86.54)$ & $<0.001^{*}$ \\
\hline \multirow[t]{3}{*}{ Circumlocution } & $2-3$ & $7 / 31(22.58)$ & $16 / 31(51.61)$ & $0.003^{*}$ \\
\hline & $4-5$ & 19/53 (35.85) & $41 / 53(77.36)$ & $<0.001^{*}$ \\
\hline & Over 6 & $39 / 52(75.0)$ & $49 / 52(94.23)$ & $0.002^{*}$ \\
\hline \multirow[t]{3}{*}{ Lateral movement } & $2-3$ & $11 / 31(35.48)$ & $26 / 31(83.87)$ & $<0.001^{*}$ \\
\hline & $4-5$ & $38 / 53(71.70)$ & $51 / 53(96.23)$ & $<0.001^{*}$ \\
\hline & Over 6 & $47 / 52(90.38)$ & $52 / 52(100.0)$ & $0.025^{*}$ \\
\hline
\end{tabular}

$* p<0.05$

아동의 혀 운동성에 대한 평가는 Fernando ${ }^{8}$ 의 Tongue tie Assessment Protocol에 근거를 두고 실시하였다. 각 과제는 혀를 앞으로 내밀기(protrusion with downward pointing), 혀를 수평 방향으로 내밀기(horizontal protrusion), 혀를 위 로 내밀기(protrusion with upward pointing), 입술 따라 돌 리기(circumlocution), 혀를 옆으로 움직이기(lateral movement)로 총 5가지로 구성되어 있다. 대상자가 수행할 수 있으 면 1점, 수행하지 못하면 0점으로 평정하였다.

아동의 자음정확도는 정상 데이터와 비교할 수 있는 표준 화된 검사 도구인 우리말 조음·음운 평가(Urimal Test of Articulation and Phonology)를 통해 측정하였다. 본 연구에 서는 혀 운동성, 자음정확도 과제를 수술 전과 수술 후 1 개 월에 측정하여 비교하였다. 수술 후, 대상자가 발음의 개선을 보일 만한 충분한 오류들을 줄이기 위해 Lee 등의 읜구와 동일하게 수술 이후의 검사 시기를 1 개월로 설정하였다.

\section{통계 분석}

통계적 분석은 SPSS 21.0(IBM Corp., Armonk, NY, USA) 을 이용하였고, 대상자의 혀 길이 및 자음정확도의 수술 전. 후를 비교하기 위해 Wilcoxon 부호 검정을 이용하였다. 또한 혀 운동성을 살펴보기 위해 대상자의 수술 전·후 및 집단 간에 카이제곱 검정을 이용하여 분석하였다. 모든 항목에서 $p$-value 0.05 미만을 통계적으로 유의한 것으로 평가하였다.

\section{결 과}

전 연령대의 설소대 단축증 아동의 수술 전 평균 혀 길이 는 $0.83 \pm 0.31 \mathrm{~cm}$ 에서 수술 직후 평균 혀 길이는 $1.93 \pm 0.51$ $\mathrm{cm}$ 로 길이가 유의하게 증가하였다. 2 3세 그룹의 경우 수술 전 평균 혀 길이는 $0.77 \pm 0.36 \mathrm{~cm}$ 였으나 수술 후 $1.82 \pm 0.47$
Table 3. Pre- and postoperative percentage of consonants correct (\%) of children with ankyloglossia

\begin{tabular}{lccc}
\hline Age (year) & Preoperative (\%) & Postoperative (\%) & $p$-value \\
\hline $2-3$ & $62.33 \pm 10.30$ & $68.86 \pm 9.29$ & $<0.001^{*}$ \\
$4-5$ & $71.15 \pm 14.22$ & $77.17 \pm 12.19$ & $<0.001^{*}$ \\
Over 6 & $85.05 \pm 14.90$ & $89.53 \pm 12.53$ & $<0.001^{*}$ \\
\hline
\end{tabular}

Values are presented as mean \pm standard deviation. $* \mathrm{p}<0.05$

$\mathrm{cm}$ 로 증가하였다. 4 5세 그룹의 수술 전 평균 혀 길이는 $0.82 \pm 0.29 \mathrm{~cm}$ 였으나 수술 후 혀 길이는 $1.93 \pm 0.55 \mathrm{~cm}$ 로 증 가하였고, 6세 이상의 그룹의 수술 전 평균 혀 길이는 $0.88 \pm$ $0.29 \mathrm{~cm}$ 였고, 수술 후 $1.99 \pm 0.49 \mathrm{~cm}$ 로 증가하였다(Table 1).

수술 전·후 혀의 운동성은 혀의 전방화 과제가 연령과 상 관없이 수술 전·후 모두 가능하였던 반면, 혀를 수평 방향으 로 내밀기 과제에서는 각 연령별로 수술 전에 비해 수술 후 에 높은 값을 보였다 $(p<0.05)$ (Table 2). 또한 혀를 상방으로 올리는 과제 및 입술 따라 돌리기 과제, 혀를 좌·우 방향으 로 움직이는 과제에서도 모든 연령군에서 수술 전에 비해 수 술 후의 운동 수행력이 유의하게 호전되었다. 특히 혀를 상방 으로 올리는 과제에서 설소대 단축증 환아가 2 3세, 4 5세 그룹에서 술전 수행 가능한 인원이 0 명과 1 명인데 비해 수술 후 12 명, 34명으로 확연히 증가하였다 $(p<0.05)$.

자음정확도 평가 결과, 2 3세 그룹에서 수술 전 자음정확 도가 $62.33 \pm 10.30 \%$ 에서 수술 후 $68.86 \pm 9.29 \%$ 으로 증가하 였으며, 4 5세 그룹에서도 술전 $71.15 \pm 14.22 \%$ 에서 술후 77.17 $\pm 12.19 \%$ 으로 향상되었다. 또한 6세 이상 그룹에서도 술전 $85.05 \pm 14.90 \%$ 에서 $89.53 \pm 12.53 \%$ 으로 향상되어, 연령과 상 관없이 모든 연령에서 수술 전에 비해 수술 후에 자음정확도 가 통계적으로 유의하게 증가하였다 $(p<0.05)$ (Table 3). 


\section{고 찰}

설소대 절제술 후 모든 연령군에서 혀의 길이가 증가하면 서 혀의 운동성이 증가하였고 자음정확도 또한 향상되었다. 수술 전·후의 차이가 가장 큰 것은 4세 이후 연령대였으며, 2 3세 그룹에서도 유의한 차이를 보이고 있음을 알 수 있었 다. 보통 말소리는 2세에 출현하기 시작하여 6세쯤 완전히 습 득되는데, ${ }^{9}$ 2 3세 아동의 경우, 짧은 설소대라는 기질적인 문 제와 완전히 이루어지지 않은 말소리 발달 때문에 혀 운동성 과 자음정확도가 가장 낮았다. 그러나 점차 완전 습득하는 말소리가 많아지는 안정기인 4세 이후부터 혀 운동성이 증가 하고 자음정확도가 높아졌다. 특히 6세 이상의 연령대에서는 짧은 설소대로 인한 발음의 오류를 보상하기 위해 스스로 발 화 시 구강을 크게 벌리지 않는 등의 방법을 사용하여 명료 도에 문제를 보이지 않는 경우도 있었다.

수술 후 아동의 평균 혀 길이는 $1.93 \mathrm{~cm}$ 로 Choi 등이이 보 고했던 3 6세 정상 아동의 평균 혀 길이 $2.1 \pm 0.36 \mathrm{~cm}$ 와 유 사한 결과이다. 또한 연령이 높아짐에 따라 혀의 최대 신장 길이도 비례함을 알 수 있었다. 설소대 단축증으로 인해 혀의 운동성 저하가 일어나게 되며 수술 후, 혀의 돌출거리 및 거 상 거리가 증가된 것은 이전 연구와 유사한 결과로 확인되었 다. ${ }^{6,11)}$ 또한 Lee 등의 의 연구에서 술후 혀의 운동성 개선여부 를 평가한 결과, 모든 연령군에서 개선되었다고 보고하였는 데, 본 연구결과 또한 이와 동일한 결과를 보였다. 발음 평가 결과 수술 후 아동의 자음정확도가 유의하게 증가하였으나 정상 아동의 평균 수준에는 미치지 못하였다. 이는 설소대 단축증 아동들은 연령이 높아질수록 자음정확도가 증가하 지만 또래의 일반 아동과 비교하였을 때 조음장애가 나타나 는 점은 선행 연구 결과와 일치하였다. ${ }^{11-13}$

많은 연구에서 공통적으로 보고된 바는 대상자의 연령이 증가함에 따라 혀의 최대 신장 길이 및 혀의 운동성이 비례 하기 때문에 만 5 세까지 수술적 치료를 보류하고 추적 관찰 을 하는 것이 적절하다고 주장하였다.5,11,14) 그러나 국내 연구 에서는 대상자 중 만 5 세 이하도 수술 전·후, 혀 운동성과 명료도가 유의하게 개선된 결과가 나타나 이전의 연구들과 상반된 결과를 보고한 바 있으며,") 설소대 절제술의 시기를 만 4 5세경에 시행하는 것이 적절하다고 하였다. ${ }^{1,11}$ 그러나 Koh 등의 읜구에서는 수술 전·후를 모두 관찰한 대상자가 17명밖에 되지 않으며, $\operatorname{Kim}$ 등 $^{11}$ 의 연구에서는 만 2 4세까지 의 설소대 단축증 아동을 대상자에 포함시키지 않는 등 작은 표본 수로 인해 연령에 따른 충분한 비교가 되지 못하였다. 본 연구에서는 2 3세 그룹에 대해서 수술 전·후, 혀 길이와 운동성 및 자음정확도에서 유의한 차이를 보고하는 바, 이
는 2 3세에도 설소대 절제술을 고려해 볼 수 있는 시기임을 시사하는 간접적인 근거로 생각된다.

본 연구를 통해 2 3세 연령에서도 설소대 절제술 후, 혀의 운동성과 발음의 개선이 있었음을 알 수 있었다. 그러나 2 3 세 연령의 표본의 수가 다른 연령군에 비해 적어 연령군별 충분한 비교가 되지 못했을 수 있으며, 수술 후 1 개월이라는 단기 결과로 장기적으로 어떤 변화를 보일지에 대한 연구도 필요할 것으로 생각된다. 또한 2 3세보다 더 어린 신생아기 때 설소대 절제술을 시행하는 경우, 그들의 영유아기 혀 운 동성과 발음 장애 여부를 살펴보는 연구가 필요할 것으로 보 인다. 수술 후 혀의 길이는 시간이 지남에 따라 재유착이나 섬유화로 인해 길이가 짧아질 수 있고, 환아의 협조가 잘 되 지 않아, 측정 시점에 따라 정확한 혀의 길이를 측정하기는 어렵다. 따라서 본 연구에서는 수술 후 마취가 된 상태에서 당기지 않고 자연스럽게 혀가 나오는 길이를 측정하여 수술 후 길어진 정도를 측정하였다. 수술 후 발생하는 재유착 여부 를 고려할 수 없었으나 수술 후 검사 시점이 1개월 뒤이므로 충분한 재유착이 이루어졌을 것으로 생각되지 않으므로, 추 후 장기적 결과를 포함한 연구가 필요할 것으로 생각된다.

본 연구를 통해 설소대 단축증 환아에서 일반적으로 알려 진 4 5세경 이후에 시행하는 설소대 절제술이 수술 후 1개월 뒤 혀의 운동성 및 자음 정확도의 측면에서 좋은 결과를 보임 을 확인할 수 있었다. 또한, 그 이전(2 3세) 연령에서도 수술 후 1 개월째 혀의 운동성, 자음 정확도가 향상되었으므로, 본 연구를 통해 설소대 절제술의 효과가 특정 연령대에 국한되 지 않는다는 근거를 마련하는 데 도움이 될 것으로 기대한다.

\section{Acknowledgments}

None.

\section{Author Contribution}

Conceptualization: Heejin Kim, Il-Seok Park. Data curation: Ju Eun Kim, Bo Ram Keum, Bin Kwon, Sung Min Park, Sung Won Li. Formal analysis: Ju Eun Kim, Heejin Kim. Methodology: Ju Eun Kim, Bo Ram Keum, Heejin Kim. Supervision: Heejin Kim, IlSeok Park. Visualization: Sung Won Li. Writing_original draft: Ju Eun Kim. Writing — review \& editing: Sung Min Park, Heejin Kim, Il-Seok Park.

\section{ORCIDs}

Il-Seok Park

Sung Min Park

https://orcid.org/0000-0001-8143-8968 https://orcid.org/0000-0001-5417-635X

\section{REFERENCES}

1) Koh JW, Ahn SJ, Yang HD, Kim BC, Shin JC. Effect of frenulotomy in tongue-tie: Focused on alveolar sounds. J Korean Soc Laryngol Phoniatr 2000;11(1):5-11.

2) Marmet C, Shell E, Marmet R. Neonatal frenotomy may be necessary to correct breastfeeding problems. J Hum Lact 1990;6(3):117-21. 
3) Greene JS. Anomalies of the speech mechanism and associated voice and speech disorders. N Y State J Med 1945;45(6):605-8.

4) Lalakea ML, Messner AH. Ankyloglossia: The adolescent and adult perspective. Otolaryngol Head Neck Surg 2003;128(5):746-52.

5) Block JR. The role of the speech clinician in determining indications for frenulotomy in cases of ankyloglossia. N Y State Dent J 1968;34(8): 479-81.

6) Lee HJ, Park HS, Park BS, Choi JW, Koo SK. The Improvement of tongue mobility and articulation after frenotomy in patient with ankyloglossia. J Otorhinolaryngol-Head Neck Surg 2010;53(8):491-6.

7) Kim IB, Han SH, Hong SJ, Yun IS, OH HS. Distribution of ankyloglossia according to length of frenum and influence of ankyloglossia in relation to angle's classification and mandibular dentition. J Korean Dent Assoc 2000;38(5):442-51.

8) Fernando C. Tongue tie--from confusion to clarity: A guide to the diagnosis and treatment of ankyloglossia. Concord, N.S.W: Tandem Publications;1998.
9) Kim SJ, Shin JY. [Articulatory and phonological disorders]. Seoul: Sigmapress;2007.

10) Choi JN, Pyo HY, Sim HS, Choi HS. A preliminary study on the determining indicatory factors for frenulotomy: Maximum lingual length-protrusion of 3-6 year old normal children with Boley Gauge (Digimatic Caliper $^{\mathbb{B}}$ ). Speech Sciences 2001;8(3):161-72.

11) Kim YD, Park SH, Chung IG, Son WS, Kim UK, Shin SH. The effect of lingual frenectomy on the tongue motion and speech. J Kor Oral Maxillofac Surg 2002;28(4):310-7.

12) Jung YJ, Moon SI, Han JW, Kim HK, Yoon SW, Kang KH. Effect of speech therapy on alveolar sound after lingual frenulotomy in tongue-tie patients. Korean J Otolaryngol 2001;44(3):317-25.

13) Cho KS. [The characteristics of development of articulation in pediatrics with ankyloglossia]. Commun Sci Disord 2001;5(2):1-11.

14) Sedano HO. Congenital oral anomalies in argentinian children. Community Dent Oral Epidemiol 1975;3(2):61-3. 